\title{
REVEALING THE EVERYDAY LANDSCAPE: INNOVATIVE SYSTEMS FOR HERITAGE EDUCATION IN SCHOOLS. THE SCAR (SCHOOL ACTIVATES RESOURCES) PROJECT
}

\author{
B. Bonfantini ${ }^{1}$, C. Casonato ${ }^{1}$, D. Villa ${ }^{1}$, N. Di Blas ${ }^{2}$, V. Pracchi ${ }^{3}$, M. Vedoà ${ }^{1}$ \\ ${ }^{1}$ Dept. Architecture and Urban Studies - Politecnico di Milano (bertrando.bonfantini; camilla.casonato; daniele.villa)@ polimi.it \\ ${ }^{2}$ DEIB nicoletta.diblas@ polimi.it \\ ${ }^{3}$ Dept. Architecture Built environment and Construction engineeering - valeria.pracchi@polimi.it
}

KEY WORDS: Cultural Heritage Education, National Digital School Plan, Skill development and communication by innovative systems, Digital storytelling

\begin{abstract}
:
The Italian Plan for Cultural Heritage Education identifies in the training related to cultural heritage the possibility of contributing to the cultural and social improvement of the life of every person, also developing, through a conscious use, the sense of belonging to one or more cultures and territory.

Given these potentialities, the document reveals a lack of responses to training needs and underlines how the launch of educational courses that put school and university in synergy in the places of culture are among the priorities to be achieved in the period 20162018. The Italian Digital School Plan also stresses the importance of a renewed educational approach and effort to promote heritage and provides that all students are offered courses on the digital management of Cultural Heritage. The interest in the heritage, after all, is identified by European policies as part of the right of every citizen to freely participate in cultural life.

The ScAR (School Activates Resources) project, aims to respond to these requests with an experimental and methodologically innovative action, set in a context rich in critical issues and on a fragile and ScARcely recognized heritage such as that of a part of the Milanese urban periphery. The aim of the project is to promote the shared knowledge of the latent urban patrimony and increase, especially in young people, the sense of belonging to the neighbourhoods, the sense of active citizenship and the responsibility in the common good's care. Another priority is to provide schools with tools for educational innovation, inclusion, and technological update, to limit early school leaving.
\end{abstract}

\section{INTRODUCTION}

This paper proposes a reflection on how advanced but easily accessible technologies can innovate the processes of heritage education in schools, increase knowledge of local culture, have a positive impact on the conservation of cultural heritage. The reflection arises from an ongoing experience and is based on various disciplines in the field (heritage preservation, representation and communication, urban planning, innovative learning strategies) to propose some considerations on the role that school can take in revealing the cultural values enclosed in the landscape of everyday life.

\section{THE SCAR PROJECT BET ON SCHOOLS (WWW.SCAR.POLIMI.IT)}

"ScAR (School Activates Resources) mends the lost heritage of the suburbs". ScAR is the title of a research project by Politecnico di Milano (the largest Italian technical university), winner of the 2017 Polisocial competition dedicated to "Suburbs". The project was recognized by the Ministry of Culture as one of the official events of the 2018 European Year of Cultural Heritage. At the centre of the project there are the seven schools involved (primary and secondary schools). However, ScAR has numerous others partners: the city administration (the Municipalities of two Milanese areas), the educational institutions (local and regional school districts), cultural actors of excellence (Fondazione Prada), experts in the support of participatory processes (MUMI, the Milan South Ecomuseum and FRCM- Fondazione Rete Civica Milano, a local civic foundation) and also associations, cooperatives, educational centres active in the neighbourhoods.

The choice of the project was to get into a context rich in critical issues and to act on a fragile landscape like that of the urban suburbs characterized by spatial and social criticalities. In this context, the project is dedicated to the teaching of "citizens in training", assigning the school the role of driving the territory, placing itself in the center of a participatory process of social cohesion and quality of life.

In line with the European Landscape Convention, the project takes on cultural heritage in a broad sense, as a system of values identified by the populations and in continuous evolution. This tangible and intangible inheritance is taken as a useful source for the promotion of intergenerational and intercultural dialogue and represents an opportunity for resilient social and territorial development.

The educational programs at the base of the project guide the participants in the recognition, description and interpretation of this system of values. The process is enhanced by technologybased activities like frame comparisons, street-level imagery, digital mapping, 3D modelling, survey from drone, 3D modelling from photography, sharing of clouds and 3D models, and digital storytelling. The experience trains students in a more expert and oriented manipulation of images and multimedia products and accompanies them in the conscious use of social sharing and communication technologies.

The aim of the project is to promote the knowledge of a little known and poorly valued heritage and increase the sense of belonging to the territory, even in students of foreign origin and their families. 


\subsection{Heritage education and citizenship}

The role of heritage education as an instrument of training for citizenship and as an inclusive and supranational identity value has long been established in Europe. In the document produced in 2006 for the Council of Europe entitled European Democratic Citizenship, Heritage Education and Identity, Tim Copeland, jointly explores the concepts of citizenship and heritage, examining the possible applications in the pedagogical field, in order to break the wrong belief that heritage and heritage education are marginal in the development of the European citizens (Copeland 2006, p. 7). Interest in heritage is also identified by European policies as part of the right of every citizen to freely participate in cultural life (Faro Convention, 2005 subscribed by Italy in 2013).

In 2015, the General Directorate for Education and Research of MIBAC (Italian Ministry of Cultural Heritage), in line with the reflection that was being developed in Europe, published the First National Plan for Cultural Heritage Education (Piano nazionale per l'educazione al patrimonio culturale).

Since then, the Plan has been updated annually with the longterm objective of «creating a heritage education system capable of involving a variety of subjects, which translates into real forms of involvement in the management and preservation of the sites of the culture and the acquisition of new and qualified knowledge, with mutual benefit for society and the heritage itself». (Direzione Generale Educazione e Ricerca, 2005). The Plan identifies in the training linked to cultural heritage the possibility of contributing to the cultural and social improvement of the life of every person, also developing, through a conscious use, the sense of belonging to one or more cultures and to the territory (MiBAC 2015, p. 7). Faced with this potential, the document notes a lack of responses to the training needs and the promotion of research in the current proposals by Italian universities. The aim of the ScAR project is to try to respond to these requests with a multifaceted experimental action, involving various activities and technologies for the understanding, interpretation, valorisation and communication of culture. In what follows, the main lines of activities are presented and discussed.

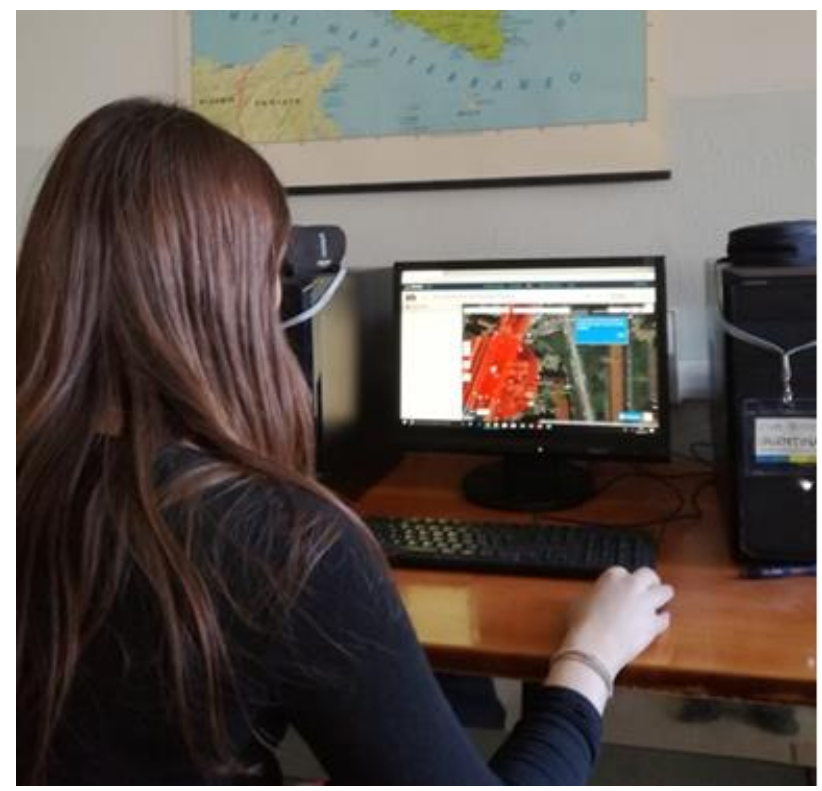

Figure 1 A student using "izitravel", a storytelling platform for cultural sites

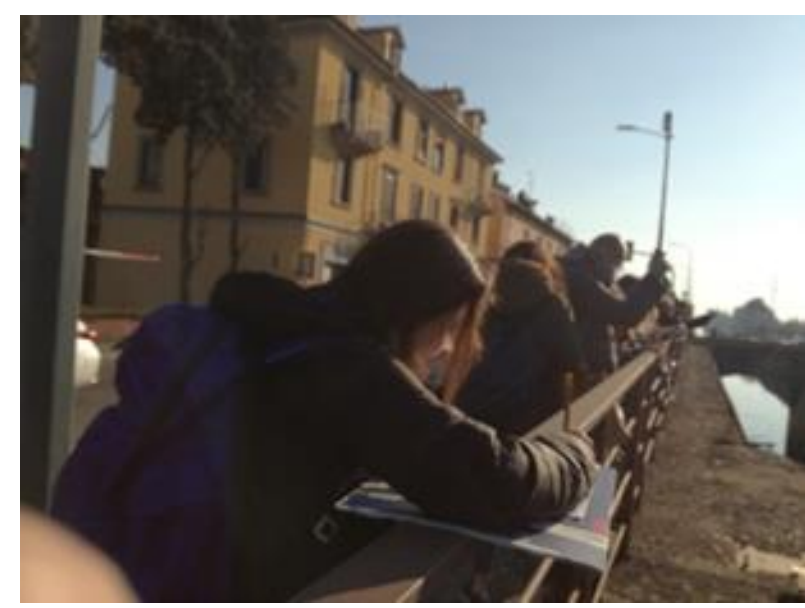

Figure 2 Students using a $360^{\circ}$ camera

\section{EDUCATION TO PATRIMONY: MEANS AND ENDS}

Even though overused (and incorrect) metaphors concerning Cultural Heritage as the Italian oil reserve are quite common, an educational policy dedicated to Heritage is not yet wide-spread. The already mentioned National Plan for education seizes this need and promotes initiatives in this regard.

Among those already put into place, the most successful was the project "Article 9 of the Constitution. Active citizens for landscape and environment", promoted by the Ministry of Education, University, and Research.

The National Digital School Plan remarks the importance of advanced technical education to heritage and provides for every student to be offered digital management courses for Cultural Heritage.

In this case too, we have numerous initiatives: for example, \#HackCultura2019 invites Italian students to develop digital projects, to favor the acquaintance with and the "taking in charge" of national legacy.

If a series of activities have been launched in schools of different levels (less in universities), nevertheless a reflection on the relationship between ends and means is still lacking.

As academics, we have the duty to increase people's acquaintance and involvement with cultural heritage and their wish to have it properly preserved.

From the article 9 of our Constitution, which entrusts the Republic with the protection of landscape and national legacy, as well as promoting the cultural development, we went to the Faro Convention in which the active role of communities is underlined. Communities are encouraged to take part in cultural life, intended as a right and duty.

It is important to raise this virtuous circle between goods and collectivity, especially with respect to what once was considered the minor heritage, which can survive only if taken in charge by the inhabitants or - in the words of the Convention - by a Heritage Community.

What we are aiming at is enhancing the desire of enjoying cultural goods, but what we are seeing - with late but serious criticism - is the creation of a new form of consumption, through the "marketing" of Cultural Heritage, as if it was a commercial product, turning citizens into clients.

The Italian cultural tourism industry has, in fact, been favoring communication strategies that bets on entertainment and, so to speak, "sensationalism". Examples are the "light and sound" shows on monumental places, where art is mediated and presented along with an ingredient meant to add a "wow" effect. The good side of this is the involvement of an audience that 
would otherwise be left out, but the downside is the lack of substantial understanding and participation. Strategies like this tend to focus on the entertainment component of portmanteau like "edutainment", forgetting the educational component that remains marginal, if not absent at all.

Although it is possible, quoting MacLuhan, that those who make a distinction between entertainment and education, perhaps do not know that education must be fun, it has not been sufficiently considered that entertainment must be educational. We must also ask ourselves if it is possible to learn about something, without any effort.

Currently, the most widespread communication strategies are based on technologies, which allow to "see more than what meets the eye": virtual reconstructions through 3D models, augmented reality, virtual reality (often available directly from mobile). The range of case is so numerous that it is impossible here to account for all of them.

These strategies are not good or bad, right or wrong per se: it depends and what they are meant to achieve. In most cases, they are "allusions" to something which is not there anymore (a typical case are archeological sites), where missing parts are reconstructed so as to offer information, sometimes accurate, sometimes just obvious ("even in the past, houses had roofs"). The risk of turning 3D models into trivial trips back in time, is very likely to occur. In all these cases, the traslation between ends and means is evident, with the latter prevailing, while the purpose of increasing curiosity, questions, knowledge, involvement, is totally betrayed.

Of course, there are many "products" of good dissemination, using light, sound, and virtual reality. The continuous sold out of the visits to various Roman archeological sites (the Foro di Cesare and Foro di Augusto and the Domus Romanae in piazza Valentini ${ }^{1}$ ), are good examples.

To sum up, these strategies show at the same time potential (especially in the case of architecture) and pitfalls and how easy it is to fall from one into the other. Potential means that these strategies could act as a stimulus to involve different kinds of visitors, to create a desire for involvement means in fact to build a knowledge request. That is where we started from and what we carefully considered in the ScAR project, having as objectives:

- To spark the interest for a fragile and poorly acknowledged patrimony such as the urban suburb, which instead has in itself important elements;

- To rediscover with new eyes the places of living;

- To raise a discussion on why we consider some places more interesting than others;

- Educate people about the importance of heritage within a logic of active involvement, as it was stated in the Faro Convention, underlining that it does not so much matter why conserving the past, but for whom we want to do it.

In the project, the underlying logic is overturned in comparison with the experiences we mentioned above, so that those who normally are not could become experts, giving them the responsibility to share their discoveries with others. In fact, the right to culture it is legitimate only if it is accessible.

\section{TECHNOLOGY AND EDUCATION: DIGITAL STORYTELLING}

Storytelling has been identified as a key strategy to convey the values of cultural heritage, providing meaning and context. Let us imagine, for a moment, a stone in our hands. A simple,

\footnotetext{
${ }^{1}$ Designed by Piero Angela with the advice of Paco Lanciano
}

unassuming, common stone, with nothing special. We would probably throw it away, not paying attention. However, what if we were told that that is the stone with which David killed Goliath? Immediately, that simple stone would turn into something else: a relic, and probably an exhibit in a museum. The story behind it would make it precious and worth seeing. This is the idea behind storytelling for cultural heritage: giving life to exhibits and artefacts that otherwise would be silent. Storytelling and digital storytelling in specific is widely employed in the field of cultural heritage communication, with the purpose of involving the visitors and providing an added value to what they see (Di Blas, Bolchini, Paolini, 2007). One example, by one of the ScAR's partners, is the multimedia communication for the restoration of Leonardo da Vinci's "Sala delle Asse" (Hall of Planks) in Milan. The hall is - at the time of writing - under restoration. A website where a number of "digital stories" can be found has the purpose of keeping the audience informed and engaged about the restoration work and providing all the necessary background to fully appreciate the masterpiece and the effort to preserve it. The "digital stories" tell, in an understandable and pleasurable way (though - of course - scientifically sound), what the lay visitor needs to know about the restoration (techniques being applied, preparatory work, approach...), the Hall of Planks (decoration, concept...) and Leonardo and his time (historical and artistic context).

In the ScAR project, a similar approach is proposed: the challenge for participating schools is to "tell stories" about their own territory, with the aim of finding something interesting, beautiful, meaningful, even where apparently there is none. Schools are invited to roam the territory, find testimonials and experts, interview them, take pictures and videos, discover minor or major cultural "episodes", events, monuments, buildings, protagonists... and make them "theirs" by getting to know them well.

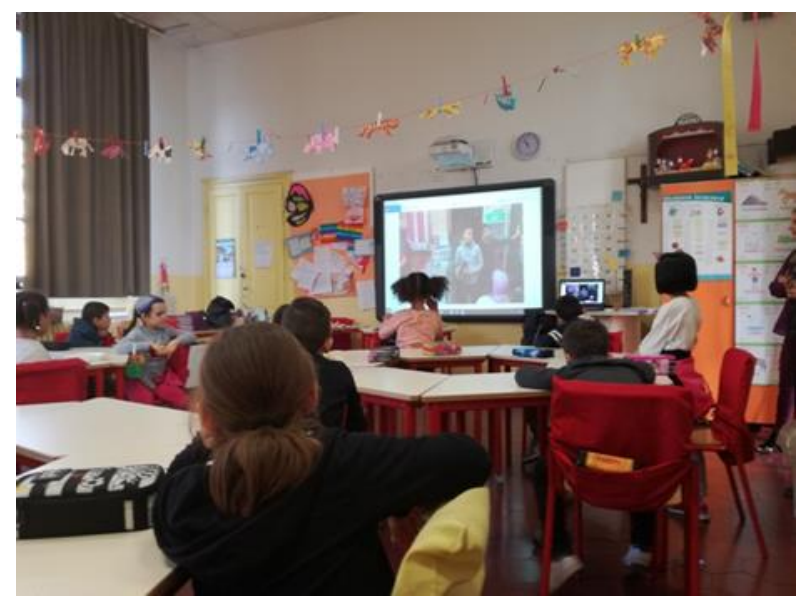

Figure 3 Primary school kids working on their storytelling

Their task is to create stories in digital form, using an authoring tool (1001stories) created by HOC-LAB at Politecnico di Milano. The tool is very easy to use and allows creating interactive "books" (with short chapters and sub-chapters) where text, videos, images and audio are combined together. The main steps to create a story are: decision on the topic to deal with, sketch of the "editorial plan" (the topics and subtopics in which the story is organized), gathering of the "raw" content (images, videos, documents, texts...), refinement of the raw content, audio-recording, upload of the materials in the authoring tool and eventually evaluation of the work (in order 
to improve it). It is a quite complex activity, through which students really get to know the topic they are dealing with (i.e. some aspects of their territory) and achieve a number of educational benefits (Di Blas, Ferrari, 2014). The goal is to have students see the place where they live with "different eyes", through the work of discovery and interpretation they go through, and hopefully get an affection towards what they have come to know.

The work is still on-going at the time of writing, but preliminary results seem promising: classes (from primary to high school) are engaged in storytelling activities, dealing with topics such as the street art in their neighbourhood or local puppet artists.

\section{ICT AND HERITAGE SHARING}

One of the strengths of the ScAR project consists in different and stratified approaches in the use of ICT for re-discovering and re-writing the ongoing history of urban cultural heritage. The approach used in ScAR capitalizes on some pilot experiences by the partners, namely the "Sacri Monti Tutti a Scuola- \#sacrimontisocial" project, and the "Sabbioneta Cerchio d'Acqua" project, two researches on Italian cultural heritage sites registered in the UNESCO world heritage list. In both cases, an innovative approach to involve young students has been developed, based on the use of digital devices and social networks.

In the case of Sabbioneta, a small Renaissance town, the project "Cerchio d'acqua" (water circle) focused on the agricultural landscape around the city wall, where actions to involve visitors were experimented. In specific, a digital treasure hunt app for elementary school children was designed. Digital technologies, in this case, were the Trojan horse pushing to look beyond the historical heritage and observe the anthropic landscape, with a holistic attitude.

In the "Sacri Monti Tutti a Scuola- \#sacrimontisocial", a research project funded by the Ministry of Culture, the basic idea was to target primary and high school students to stimulate awareness and a conscious and creative use of mobile devices and social networks to collect and share personal points of view, visual storytellings, drawings and sketches around the nine "Sacri Monti" (literally, "Sacred Mountains") which can be found in North-East Italy (Piedmont and Lombardy region). The Sacri Monti usually comprises a "holy road" with chapels and a sanctuary. In this two-years collaborative and inclusive project, which involved over 460 students from 18 schools, one of the most rewarding result was the level of active participation by the students, even after the end of the work with the academic tutors. Students showed a strong capability to adapt their digital behaviours to the goals of the assignments, focusing on the visual elements and with a continuous interest for hybridization of graphic and communicative outputs. Moreover, the project is still participated: content is growing freely and spontaneously on the many social platforms available, under the hashtag \#sacrimontisocial and it is being collected on a webhub (http://www.sacrimonti.polimi.it) where cross-thematic search that includes all the nine "Sacri-Monti" is possible.

These two case studies are framed in a broader view of cultural heritage communication where visual representation is the cornerstone. Since personal digital devices and social tools have become ubiquitous, it is now essential to adapt our scientific approaches to the various ways in which knowledge concerning cultural heritage is produced (and shared), especially by younger generations.

\section{6. “DIGITAL EXPERIMENTS" IN SCAR}

Leveraging on the power of new technologies to engage people and youngsters in particular, ScAR means to achieve a two-fold objective: on one side, to connect youngsters with cultural heritage and on the other educate them to a proper use of new sharing - technologies.

As mentioned before, the area of interest of the project are suburban areas in the city of Milan. Before starting the activities, it was necessary to "catalogue" what was to be found in these areas, to have a database of content to start from. The initial cataloguing process, which was performed with an archival and an on-field research, was the opportunity to test one of these technologies: the "open webGIS" (www.ScAR.polimi.it/\#territorio). The webmap gathers the tangible and intangible elements of the cultural landscape where ScAR is active, such as stories, images, and historical records, that have been identified during the analysis. This tool has been essential to set the activities, because the map shows where the cultural heritage is located; in addition, it has proved a valuable tool for the cultural landscape education. The mere fact that the map highlights how rich in terms of cultural heritage the territory is, allows the user to perceive its value. Considering the educational value of a digital map, an open mapping tool has been provided not only to teachers and students involved in the project, but also to anyone who may want to contribute to the valorisation of the cultural landscape of the ScAR area. The "Atlante Digitale delle Memorie" developed by MUMI (an ecomuseum based in the South of Milan) is a geoblog based on OpenStreetMap. Users can map and share information and impressions on the cultural landscape; the act of mapping becomes itself a relevant tool for the cultural heritage education. The learning tours gave the opportunity to use a 360 -camera to document the cultural landscape. Indeed, spherical images offer a proper point of view for the cultural landscape communication; they set the observer at the center of an immersive scene, which was also enriched with original audio files and interviews. Additionally, these immersive scenes can be easily handled and created with free online software like Mapillary - an online service for creating immersive georeferenced timeline - and Google Tour Creator, which allows teachers and students to develop complex AR and VR tours, even with a basic IT knowledge. "Experience Tour of the Stadera Neighbourhood" is an augmented reality tour created with Google Tour Creator, which can be performed with simple and inexpensive tools: a smartphone and VR goggles like Google CardBoard.

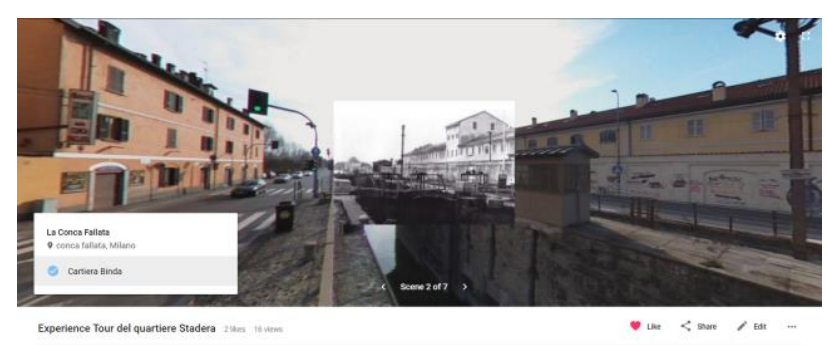

Figure 4. "Experience Tour of the Stadera Neighbourhood"

In this tour, the user explores immersive scenes with ambient sounds and storytelling in which historical images can be overlapped to the actual spherical photo. 
This application enables the user to recognize the value of the cultural heritage and understand how landscape has changed through history. The experience tour, which was presented during the Milano Digital Week 2019, is the result of field trips and research by the students involved in the project. Moreover, the development of the content, the spherical images, and audio files was itself part of the educational process, because the students have acted as active performer during the tour development.

Alongside the development of the VR and AR tours, ScAR has run two other immersive storytelling activities that involve a gamification process. In the first, high school students were invited to create a mobile touristic guide with Izi.travel, which is an online and free content management system (CMS) specially designed for tour operators. This mobile app allows students to develop professional tourist guides for the ScAR area, in which cultural heritage elements are the main stops.

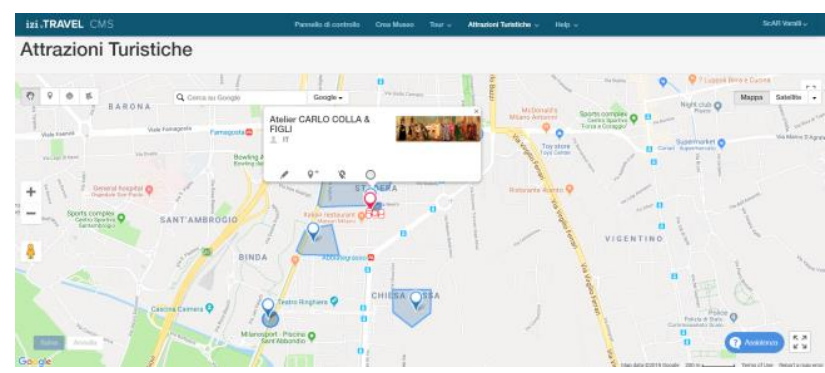

Figure 5. Back end of the CMS Izi.

The second tool, GaiaSmart, is instead a mobile app that allows people to discover the cultural landscape through an on-site geogame. High-school students were invited to develop the game: first, they identified the points of interests and then they developed the contents, such as images, text and the questions for the game.

\section{PROXIMITY URBAN PLANNING AND THE SCHOOLS AS AN ENGINE OF "DENSE" REPRESENTATION OF THE CITY}

The "participation games" as "territorial forms of collective actions" (Savoldi, 2006) are a constant - almost a commonplace - of the decision-making processes in recent decades. But these experiences of people involvement, even before any concrete action follows, are reflected in the construction of a common local "imaginary".

In large cities, this local-oriented look is often intertwined with their minute administrative geography. In fact, Italian cities are often divided into "municipi" and "quartieri" (boroughs) that offer spaces - including institutional facilities - for the development of urban policies rooted in the local context. This look can also be intertwined with the urban planning forms and contents developed in relation to the multiple "micro-cities" that can be identified in the urban settlement. The expression "microcity" ("microcittà") was used during the elaboration of the recent urban plan of Rome (see Modigliani, 2001, 74; Pietrolucci, 2017). A study conducted by Cresme for that plan was able to recognize about 200 different urban entities inside the city, in the specific characterizing relationships between space and society (Cresme, 1999). In the urban plans of Bologna (2008) and Milan (2012) respectively, the "Situazioni" (urban situations, or local urban environments) and "Nuclei
d'Identità Locale" (NIL, nuclei of local identity; Russi, 2009) investigate similar urban geographies. Situazioni and NIL speak of the urban landscape through the lens of toponyms, i.e. places in space and time, while composing them in local environments that reveal their distinction and "density" of places.

These representations of the city through local environments share common features with the eco-museum initiatives, defined as "a participatory practice of valorisation of the tangible and intangible cultural heritage developed by the local community also through an organization - in the perspective of a sustainable development". However, it is precisely the notion of community - the idea that there may be such a subject - that appears slippery, in a historical phase that experiences the "disjunction" between space and society (Pasqui, 2008), as well as the notion of identity, which is often associated with it as a goal to pursue or a value to defend.

Leaving aside self-referred and defensive identity objectives (Remotti, 2013; 2017), it seems more interesting to look at these urban geographies in their potential openness and generativity. They may be dense representations of places as an expression of (active parts of) local societies in transformation that in the discovery and discussion of tangible and intangible elements rooted in space and time of their local environment can find opportunities for the construction of a new imaginary for the future. The intent seems to consist precisely in representing "full" - that is, "dense"- metropolitan situations, such as the peripheral urban districts, which instead are typically perceived as empty, deprived of meaning and territorial values.

Fifty years after the introduction of the "planning standards" (Renzoni, 2018), the reflection on the potential role of schools as a cultural hub for their territory is renewed (Consalez, 2018). ScAR research addresses these issues testing the potential of schools as a driving force in the recognition and construction of local cultural heritage systems. The disappearance of traditional catchment areas and of a homogeneous school population makes this exercise of territorial representation more and more interesting, as an operation based not on belonging but rather on exploration, discovery, encounter and re-signification.

"Why roots and not wings? Why not to think that identity can also be defined in terms of a future to be shared, rather than a past to be contemplated?" (J.O. Prenz. in De Santis, 2019: 32).

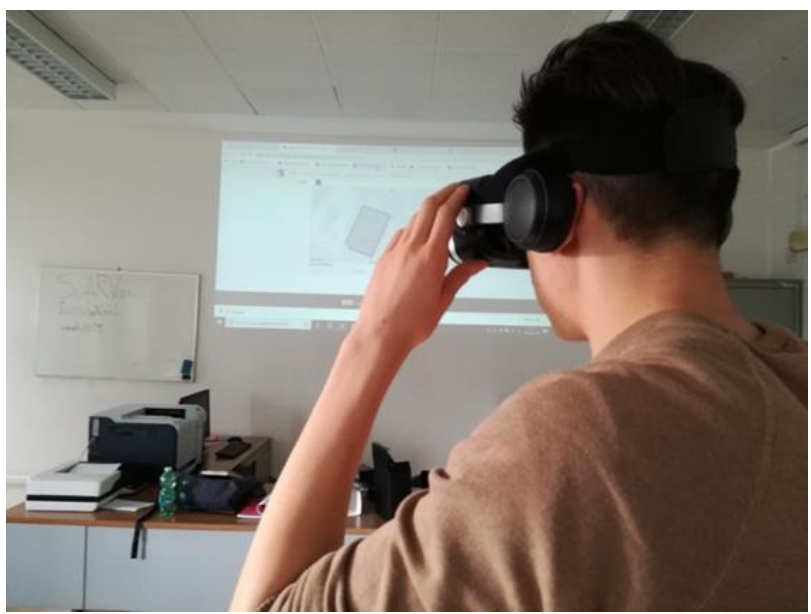

Figure 6. Augmented Reality and Virtual Reality at high school 
This paper is the result of a joint project and is fully shared among the authors; the manuscript was drawn up as follows: paragraph 1 and 2 by Camilla Casonato; paragraph 3 by Valeria Pracchi; paragraph 4 by Nicoletta Di Blas; paragraph 5 and 6 by Daniele Villa and Marco Vedoà; paragraph 7 by Bertrando Bonfantini.

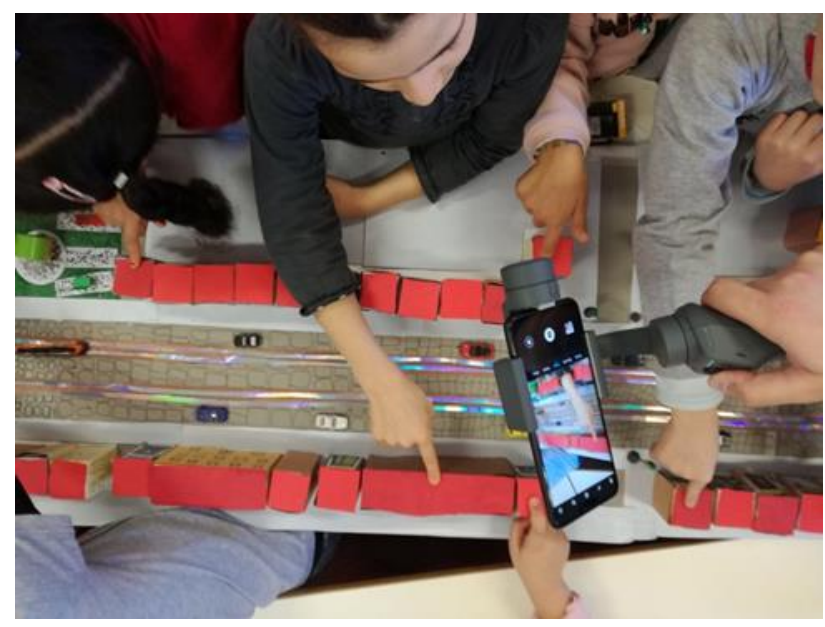

Figure 7. Primary school students record (through "gimbal") the use of maquette (models) to represent their territory.

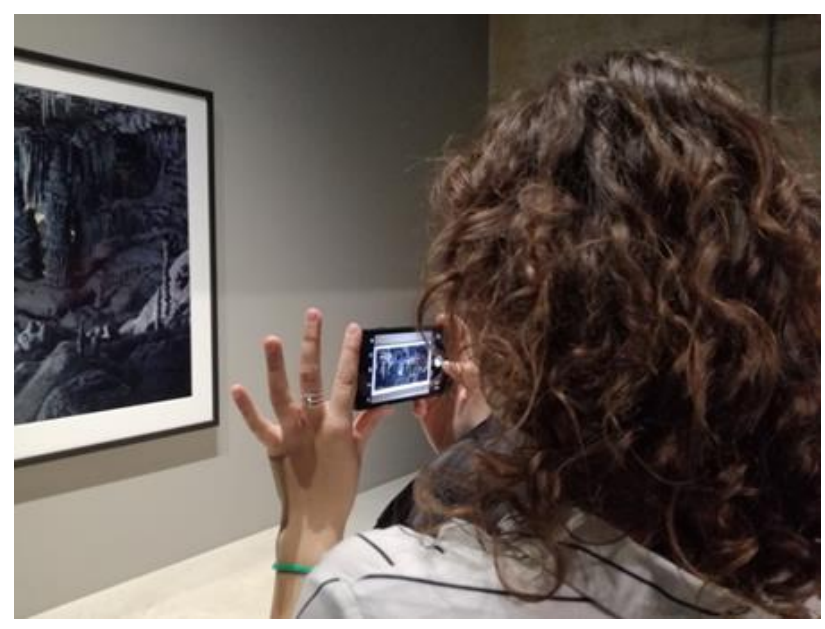

Figure 8. Students share art through social media (Fondazione Prada)

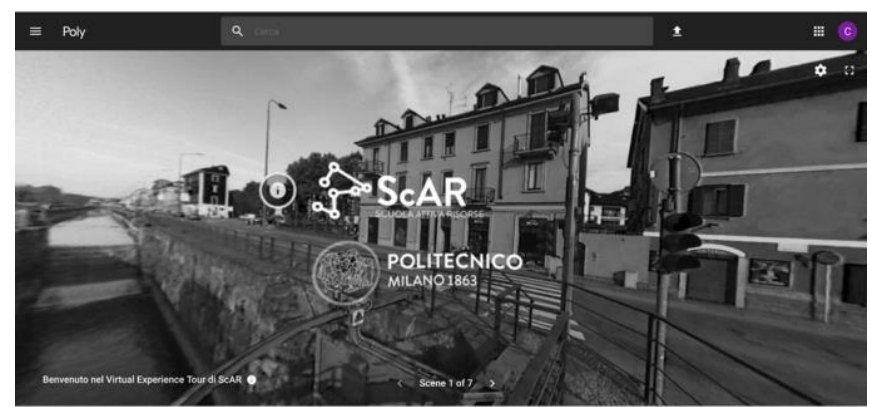

Figure 9 Virtual tour Naviglio Pavese with google VR from $360^{\circ}$ images

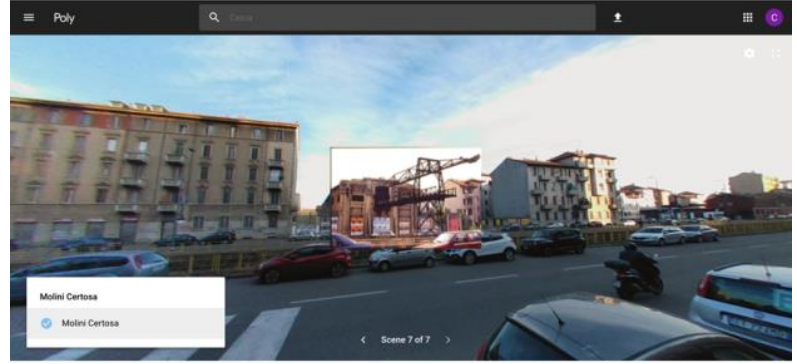

Figure 10. Visualizing the landscape with immersive modalities using frame comparisons in augmented reality: the Certosa Mills currently dismissed

\section{ACKNOWLEDGEMENTS}

This work presented in this paper is funded by PoliSocial, the social responsibility programme by Politecnico di Milano (Italy). Authors warmly thank all the participants - teachers and students - who make all this possible.

\section{REFERENCES}

Consalez, L., 2018. "Un ponte tra scuola e territorio", Territorio, n. 85, pp. 80-92.

Copeland, T., 1998. Whose monuments are they? Whose past is it? The multicultural use of monuments. In COUNCIL OF EUROPE (a cura di), 1998. Cultural heritage and its educational implications: a factor for tolerance, good citizenship and social integration. Strasbourg: Council of Europe Publishing, pp. 39-43.

Copeland, T., 2006. European democratic citizenship, heritage education and identity. Strasbourg: Council of Europe Publishing.

Cresme - Centro ricerche economiche e sociali del mercato dell'edilizia (1999), Verso il nuovo piano regolatore . Centralità Nuove municipalità Identità, Comune di Roma, Dipartimento alle Politiche del Territorio, Ufficio Nuovo Piano Regolatore, Roma.

De Santis, R., 2019. "Il Nonino agli autori contro il sovranismo", La Repubblica, giovedì 10 gennaio, p. 32 .

Di Blas, N., Bolchini, D., \& Paolini, P., 2007. Instant multimedia: A new challenge for cultural heritage. In Museums and the Web 2007 (pp. 1-12). Archives \& Museum Informatics.

Di Blas, N., \& Ferrari, L., 2014. Digital storytelling at school: what kind of educational benefits? International Journal of Arts and Technology, 7(1), 38-54.

Macdonald, L.W., 2006. "Digital Heritage: applying digital imaging to cultural heritage", Elsevier.

Modigliani, D., 2001. "Piani, programmi e azioni per la periferia”, Urbanistica, n. 116, pp. 74-82.

Morisette, L.K., 2011. La ville phénomène de représentation, Montreal, Presses de l'Université du Québec, 
Pasqui, G., 2008. Città, popolazioni, politiche, Jaca Book, Milano.

Pietrolucci, M., 2017. Verso la realizzazione delle 'microcittà' di Roma, Skira, Milano.

Priore, R., 2009. No People, No Landscape: la Convenzione Europea del Paesaggio. Luci ed ombre nel processo di attuazione in Italia. Milano: Franco Angeli, pp. 288.

Remotti, F., 2013. Contro l'identità, Laterza, Roma-Bari.

Remotti, F., 2017. L’ossessione identitaria, Laterza, Roma-Bari.

Renzoni, C., (a cura di) 2018. "Cinquant'anni di standard urbanistici (1968-2018). Radici”, Territorio, n. 84, pp. 21-76.

Russi, N., 2009. "Progettazione alla scala locale. I Nuclei di identità locale del Pgt di Milano", in Pomilio, F., (a cura di), Welfare e territorio. Esplorare il legame tra politiche dei servizi e dimensione urbana, Alinea, Firenze, pp. 133-146.

Savoldi, P., 2006. Giochi di partecipazione. Forme territoriali di azione collettiva, Franco Angeli, Milano.

\section{Documents (in chronological order)}

Convenzione Europea del Paesaggio, Firenze 2000.

Convenzione di Faro, Convenzione Quadro del Consiglio d'Europa sul valore del patrimonio culturale, Faro 2005.

International Council on Monuments and Sites (ICOMOS), 2014. Dichiarazione di Firenze, principi circa il valore dell'eredità culturale e del paesaggio per la costruzione di una società di pace e democrazia.

Ministero per i Beni e le Attività Culturali (MiBAC), Direzione Generale Educazione e Ricerca, 2015. Primo Piano Nazionale per l'educazione al patrimonio culturale.

[visited the 26th of november 2018] Avaliable from: http://www.dger.beniculturali.it/index.php?it/21/news/6/pianonazionale-per-leducazione-al-patrimonio-culturale.

Ministero dell'Istruzione, dell'Università e della Ricerca (MIUR), 2015. Piano Nazionale Scuola Digitale.

Council of Europe, 2016. Landscape Dimensions, Reflections and proposals for the implementation of the European Landscape Convention. Strasbourg: Council of Europe Publishing.

\section{Sitography}

Direzione Generale Educazione e Ricerca. Direzione Generale Educazione e Ricerca. 2005 [visitato il 26 novembre 2018]. Disponibile da: http://www.dger.beniculturali.it.

Scuola Attiva Risorse. Politecnico di Milano. 2018 [visitato il 26 novembre 2018]. Disponibile da: www.ScAR.polimi.it.

Anno europeo del patrimonio culturale 2018. Ministero per i Beni e le Attività Culturali. 2018 [visitato il 26 novembre 2018]. Disponibile da: http://annoeuropeo2018.beniculturali.it/.
Ecomuseo Milano Sud. Ecomuseo Milano Sud. 2017 [visitato il 26 novembre 2018]. Disponibile da: https://www.mumiecomuseo.it/. 